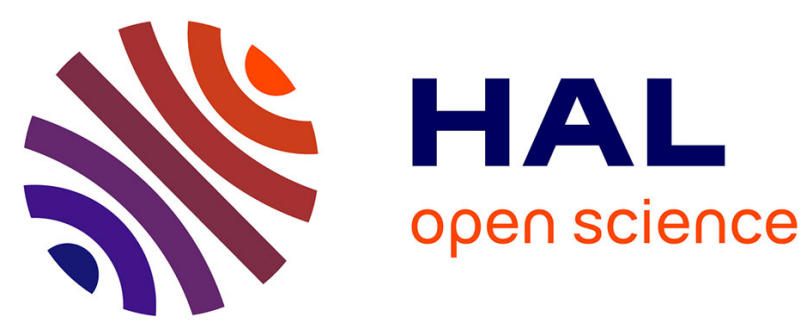

\title{
OnoM@p: a Spatial Data Infrastructure dedicated to noise monitoring based on volunteers measurements
}

Erwan Bocher, Gwendall Petit, Nicolas Fortin, Judicaël Picaut, Gwenaël Guillaume, Sylvain Palominos

\section{- To cite this version:}

Erwan Bocher, Gwendall Petit, Nicolas Fortin, Judicaël Picaut, Gwenaël Guillaume, et al.. OnoM@p : a Spatial Data Infrastructure dedicated to noise monitoring based on volunteers measurements. OGRS2016, Open Source Geospatial Research \& Education Symposium, Oct 2016, PEROUSE, Italy. 11p, 10.7287/peerj.preprints.2273v2 . hal-01373694

\section{HAL Id: hal-01373694 \\ https://hal.science/hal-01373694}

Submitted on 29 Sep 2016

HAL is a multi-disciplinary open access archive for the deposit and dissemination of scientific research documents, whether they are published or not. The documents may come from teaching and research institutions in France or abroad, or from public or private research centers.
L'archive ouverte pluridisciplinaire HAL, est destinée au dépôt et à la diffusion de documents scientifiques de niveau recherche, publiés ou non, émanant des établissements d'enseignement et de recherche français ou étrangers, des laboratoires publics ou privés. 


\title{
OnoM@p : a Spatial Data Infrastructure dedicated to noise monitoring based on volunteers measurements
}

\author{
Erwan Bocher ${ }^{1}$, Gwendall Petit ${ }^{1}$, Nicolas Fortin ${ }^{2}$, Judicaël Picaut ${ }^{2}$, Gwenaël Guillaume ${ }^{2}$, \\ and Sylvain Palominos ${ }^{1}$ \\ ${ }^{1}$ Lab-STICC laboratory - CNRS UMR 6285 / UBS, DECIDE team, Vannes, France \\ ${ }^{2}$ L'UNAM Université, IFSTTAR, AME-LAE laboratory, Nantes, France \\ Corresponding author: \\ Erwan Bocher ${ }^{1}$ \\ Email address: erwan.bocher@univ-ubs.fr
}

\begin{abstract}
The present paper proposes an ideal Spatial Data Infrastructure (SDI) dedicated to noise monitoring based on volunteers measurements. Called OnoM@P, it takes advantage of the geospatial standards and open source tools to build an integrated platform to manage the whole knowledge about a territory and to observe its dynamics. It intends also to diffuse good practices to organize, collect, represent and process geospatial data in field of acoustic researches.

OnoM@p falls within the framework of the Environmental Noise Directive (END) 2002/49/CE. The system relies on the NoiseCapture Android application developed for allowing each citizen to estimate its own noise exposure with its smartphone and to contribute to the production of community noisemaps.
\end{abstract}

Keywords: Noise, GIS, SDI, OGC, spatial analysis, crowdsourcing, VGI, smartphones

\section{INTRODUCTION}

In 2015 , more than 7 billion people (i.e. $96,4 \%$ of the world's population ${ }^{1}$ ) owns a mobile phone subscription 2 . While in that year only $31 \%$ of sold phones were smartphones, the smartphone sales position in the phone market is widening with 446 million units sold only during the second quarter of 2015. This growth affects all countries. For example, Deloitte company considers that "The smartphone market will grow by over $40 \%$ in 2015 with 70 million copies will be sold in Africa". These communication devices benefit from the technology advances in consumer electronics, and integrate an increasing number of sensors, including for the latest versions position sensors (GPS), motion sensors (accelerometer, gyroscope) and environmental sensors (microphone, camera, temperature sensor, photometer, barometer). In addition, the significantly growing computational power of smartphones and their Internet connectivity increase their attractiveness at once for the public, the

\footnotetext{
${ }^{1}$ https://esa.un.org/unpd/wpp/Download/Standard/Population/ (accessed in july 2016)

${ }^{2}$ https://www.itu.int/en/ITU-D/Statistics/Pages/stat/default.aspx (accessed in july 2016)

3 http://www.smartphonemarketresearch.com (accessed in july 2016)
} 
public authorities and business.

In this context, the idea to rely on smartphones for initiating a new relation between the citizens and the environmental stakes is naturally emerging, for which the citizen would play a dual role of consumer and producer of environmental information. The participatory sensing concept rests on user-centric monitoring and environmental sensing by means of smartphones (Burke et al., 2006). This notion recently arisen as a low-cost alternative to large-scale and costly infrastructures sensing based on sensor networks (Cuff et al., 2008). Thus, numerous approaches were developed based on citizen-centric surveys (Andrew T. Campbell and Peterson, 2006), (Adeel et al., 2014) and opportunities to volunteer to take part into scientific research projects in environmental monitoring (Conrad and Hilchey, 2011). The OpenStreetMap project (OSM 4 ) is the leading example of the effectiveness of citizen participatory with more than 2.8 million registered members by july $2016^{5}$. With the emerging demands of open geodata, OSM made one of the most used non-proprietary online maps and an input for numerous third-parties (Neis and Zipf, 2012). The citizen can thus become a main actor by monitoring his environment and sharing his measurements or observations concerning his territory of life.

Several applications were recently developed for the purpose of noise levels measurements (Leao and Zhou., 2014), as for example NoiseTube (Maisonneuve et al., 2010), (D'Hondt et al., 2013), (Drosatos et al., 2014), WideNoise (Becker et al., 2013), NoiseSpy (Kanjo et al., 2009), (Kanjo, 2010), NoizCrowd (Wisniewski et al., 2013), Noise-Watch (Nugent and Stanners, 2014), SoundOfTheCity (Ruge et al., 2013), etc. However, (Guillaume et al., 2016) point out some scientific and technological bottlenecks :

- mobile phones agents would mainly measure their daily sound exposure while the Directive 2002/49/EC fixed at least two indicators that are much less covered,

- lack of proper validation both for sound measures and GPS location,

- components of these applications does not rely sufficiently on standards, particularly those of the GIS community.

In this context, a Spatial Data Infrastructure (SDI) integrating a Geographic Information System (GIS) enables the use of spatial and environmental data in an efficient and flexible way and remains an ideal framework to fulfill this last point (Mohammadi et al., 2008). Indeed, since 2000s, the GIS community made progress and efforts to define open standards to enhance geospatial data exchange and sharing. These standards, mainly defined by the Open Geospatial Consortium are the main fuel to set up integrated platform, to facilitate the interconnection of systems and the carrying out of systemic approaches (Steiniger and Hunter, 2012). They offers protocols, conceptual models and format to:

- store and query data : Simple feature access - Part 1 and 2, GeoSPARQL...

${ }^{4}$ https://www.openstreetmap.org/ (accessed in july 2016)

5 http://www.openstreetmap.org/stats/data_stats.html (accessed in july 2016) 
- style data : Symbology Encoding (SE) 6

- deliver data : Web Mapping Service (WMS)7, Web Feature Service (WFS $)^{8}$..

- search data : Catalogue Service (CSW) 9 , Gazetteer Service (WFS-G)...

- deliver and manage processing : Web Processing Service (WPS ${ }^{10}$ ) and Web Coverage Processing Service (WCPS).

The present paper proposes an ideal Spatial Data Infrastructure (SDI) dedicated to noise monitoring based on volunteers measurements. Called OnoM@P, it takes advantage of the geospatial standards and open source tools to build an integrated platform to manage the whole knowledge about a territory and to observe its dynamics. It intends also to diffuse good practices to organize, collect, represent and process geospatial data in field of acoustic researches. Indeed, through this platform and its technical issues, several scientific locks are addressed :

- How to store and describe multiscale and temporal data collected from smartphones?

- What kind of language to query the data that makes sense for geographer, acousticians, developers... ?

- How to enable the integration between noise measures and GIS layers as OSM?

- How to aggregate data to produce human understandable and scientific results?

- How to map raw data or results that are scale and time dependant?

\section{THEONOM@P SDI}

OnoM@p is an open source Spatial Data Infrastructure dedicated to noise monitoring based on volunteers measurement. OnoM@p is developed within the framework of the ENERGIC-OD 11 project that aims at deploying a set of Virtual Hubs $(\mathrm{VH})$ based on a broker approach to offer to both end-users (through geoportals) and machines (web services, applications), unique and mutually consistent access points to heterogeneous data sources, including INSPIRE-compliant systems and Copernicus ${ }^{12}$ GMES ${ }^{13}$ services.

\section{System components and standards}

The OnoM@p system is divided in two components (Figure 1) : The "NoiseCapture" application and the server side services (Virtual hub).

\footnotetext{
${ }^{6}$ http://www.opengeospatial.org/standards/se (accessed in july 2016)

7 http://www.opengeospatial.org/standards/wms (accessed in july 2016)

${ }^{8} \mathrm{http} / / /$ www.opengeospatial.org/standards/wfs (accessed in july 2016)

shttp://www.opengeospatial.org/standards/cat (accessed in july 2016)

${ }^{10}$ http://www.opengeospatial.org/standards/wps (accessed in july 2016)

${ }^{11} \mathrm{http}: / /$ www.energic-od.eu/ (accessed in july 2016)

${ }^{12}$ http://WwW.copernicus.eu/ (accessed in july 2016)

${ }^{13}$ http://www.esa.int/About_Us/Ministerial_Council_2012/Global... (accessed in july 2016)
} 


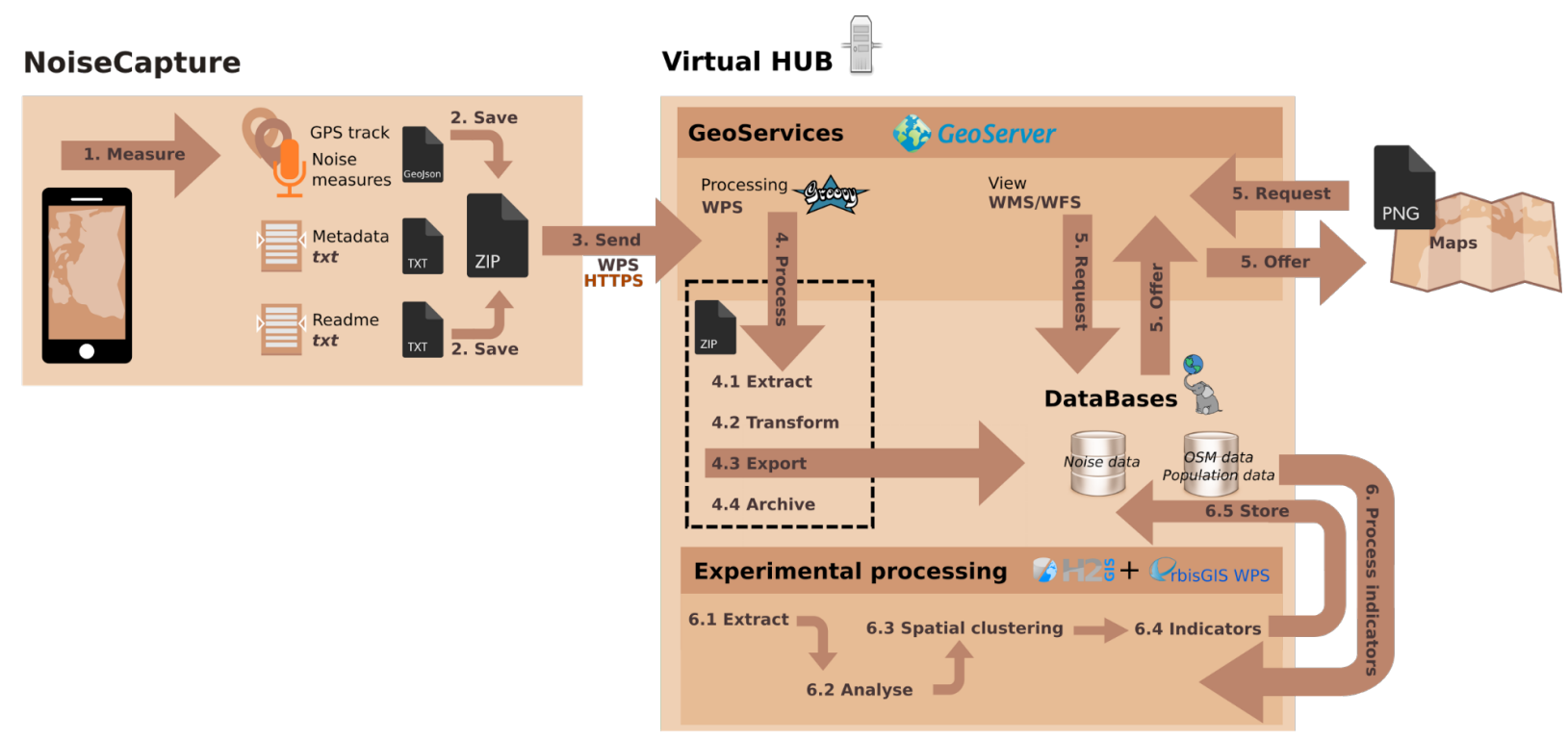

Figure 1. The OnoM@p system components.

\section{The NoiseCapture application}

NoiseCapture is an Android application to collect noise measure at given locations. Noise indicators are computed on the smartphone device during a period of time specified by the user. The main functionalities are the following (Figure 2) :

- Measurement (Figure 2(a)): Once the sound level calibration is done, the user start the measurement in order to record each second the LAeq (a weighted equivalent sound level), an average of the sound energy over a period of $1 \mathrm{~s}$. The noise spectrum repartition is also analysed using the Fourrier transform. The device locations are recorded while measuring the sound level. The user has also the ability to provide his own feedback about the feeling of the noise environment.

- Extended report: Advanced statistics are computed locally on the phone and shown to the user (Figure 2(b)). For each user's measurement the locations of the noise levels are displayed in a map (Figure 2(c)).

- Share results with the community: Anonymized results are transferred to Virtual Hubs (web server) and post-processed in order to build a noise map that merge all community results.

\section{The server side services}

The server side services are hosted on the French part of the Energic-OD Virtual Hub. They are organized around a Geoservices component, a relational database management system and an experimental processing module.

\section{The Geoservices}

The Geoservices component uses the GeoServer application and a plugin to support Web Processing Services (WPS). This WPS plugin is used to push from the smartphone to a relational database a 


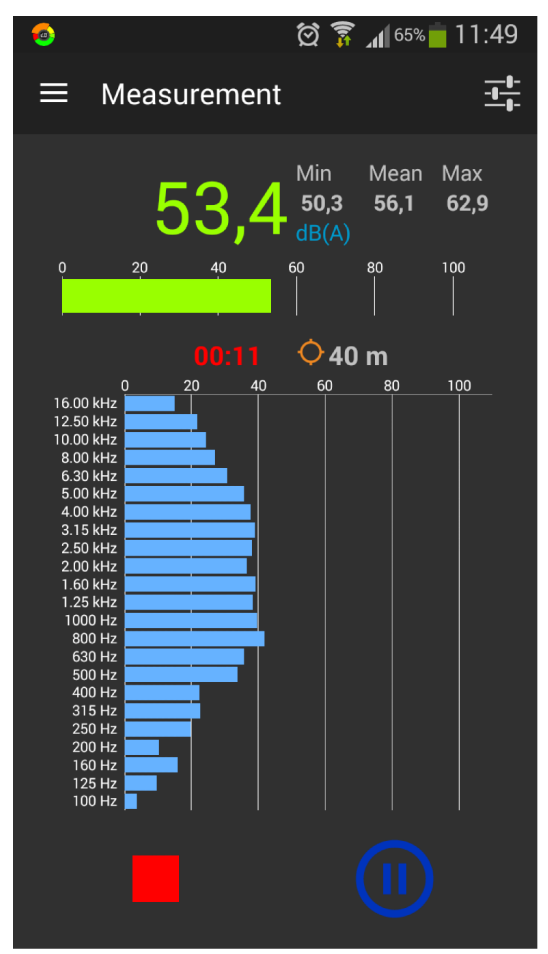

(a)

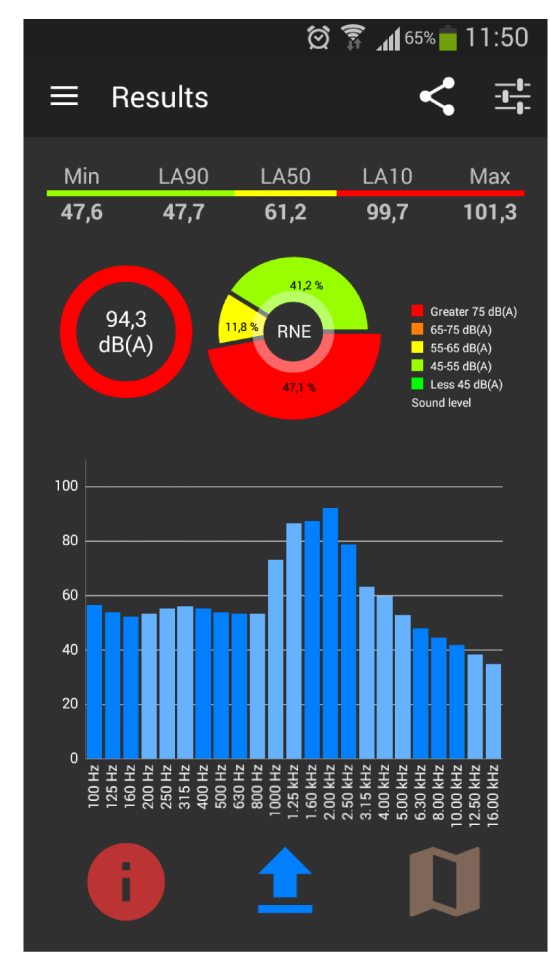

(b)

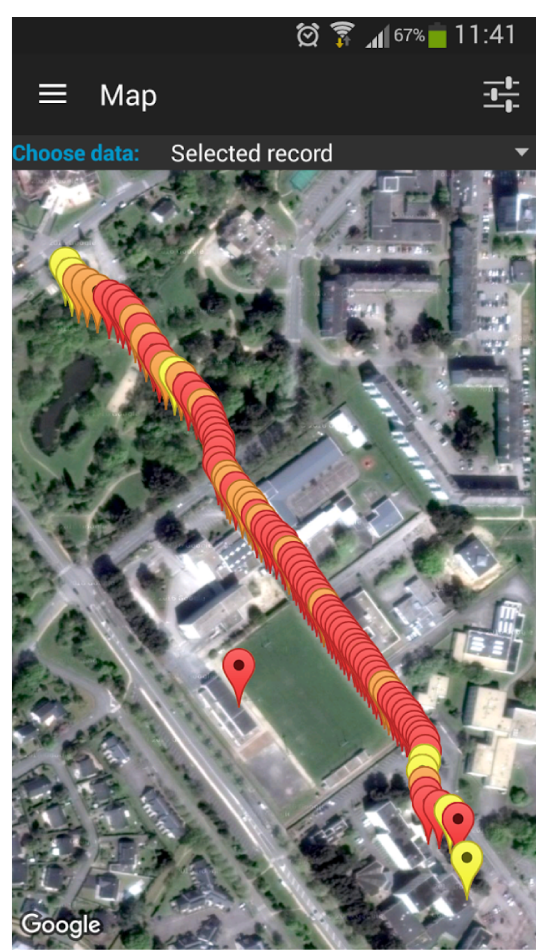

(c)

Figure 2. Screenshots of the NoiseCapture application: (a) measurement screen, (b) results screen and (c) noise level visualization on a map.

zipped file.

The zipped file contains 3 files:

- a geojson file, that stores all track coordinates and the noise indicators computed along the track,

- a metadata file that concatenates some metadata concerning the smartphone and the measurement such as the calibration method,

- a readme file that contains some details, definitions about the noise indicators.

Once the data uploaded, a 4 sub-steps process is run, thanks to the Groovy language:

- Extract: First of all, the zipped file is analysed to avoid security problems, then the file is unzipped and 3 files are stored in a temporary folder,

- Transform: The geojson and the metadata files are parsed and transformed into SQL scripts,

- Export: The SQL scripts are uploaded on a Noise database,

- Archive: The input zipped file is archived into a specific folder. 
The rendering module of the Geoserver application is connected with the Noise database to offer on demand a set of maps using the WMS standard and the raw data using the WFS / GeoJson standard.

\section{The relational database management system}

Two spatial databases are built to store the data collected and needed by the OnoM@p system. These databases use the RDMS PostgreSQL ${ }^{14}$ with the Postgis ${ }^{15}$ extension.

The first database stores all data collected from the NoiseCapture application and some experimental indicators (i.e. noise population exposure). The second one is shared by the French Energic-OD hub and delivers common data set required by the applications. For example, the French statistical geographic zones (IRIS) or the French census statistics (INSEE ${ }^{16}$ ).

\section{The experimental processing module}

This module is implemented on top of the H2GIS database (Bocher et al., 2015) and the OrbisGIS WPS server (Bocher and Petit, 2013). It contains an experimental chain of spatial and statistical analysis methods to compute new indicators from research work. This module is compliant with the last version of the WPS standard (WPS 2.0).

\section{Operating mode}

The OnoM@p system is an integrated platform which covers all workflow and lifecycle stages to collect, compute, share and display noise data and at the end inform the user about its noise exposure. In the OnoM@p ecosystem, we consider four levels of stakeholders who will play a role (Figure 3).

\section{VGI (Volunteered geographic information)}

The volunteer collects noise data from its smartphone and publishes it on the OnoM@p database. The volunteer must respect some guidelines to obtain a good measure. This guidelines are not constrained by the application. It's up to the volunteer to follow best practices such as:

- the smartphone has to be outside the clothe's pockets,

- the smartphone has to be in the hand (e.g. not on a table),

- the microphone has to be free (no mask),

- the volunteer should walk (instead of running or biking),

- the measure must be done outside a building,

- the measure must be done when the GPS signal is correct (e.g. not in a tunnel, ...).

Nevertheless, the WPS operation in charge of indicators computation integrates a post-process analysis to control the quality of the measure. The uncertainty of the microphones and the precision of the GPS locations are estimated, taking account of the time period of each records. Finally bad located measures are excluded from the chain of indicators and noise maps.

\footnotetext{
${ }^{14}$ https://www.postgresql.org/ (accessed in july 2016)

${ }^{15}$ http://postgis.net/ (accessed in july 2016)

${ }^{16} \mathrm{http}: / / \mathrm{www} . \mathrm{insee}_{\mathrm{fr}} / \mathrm{en} / \mathrm{default}$.asp (accessed in july 2016)
} 

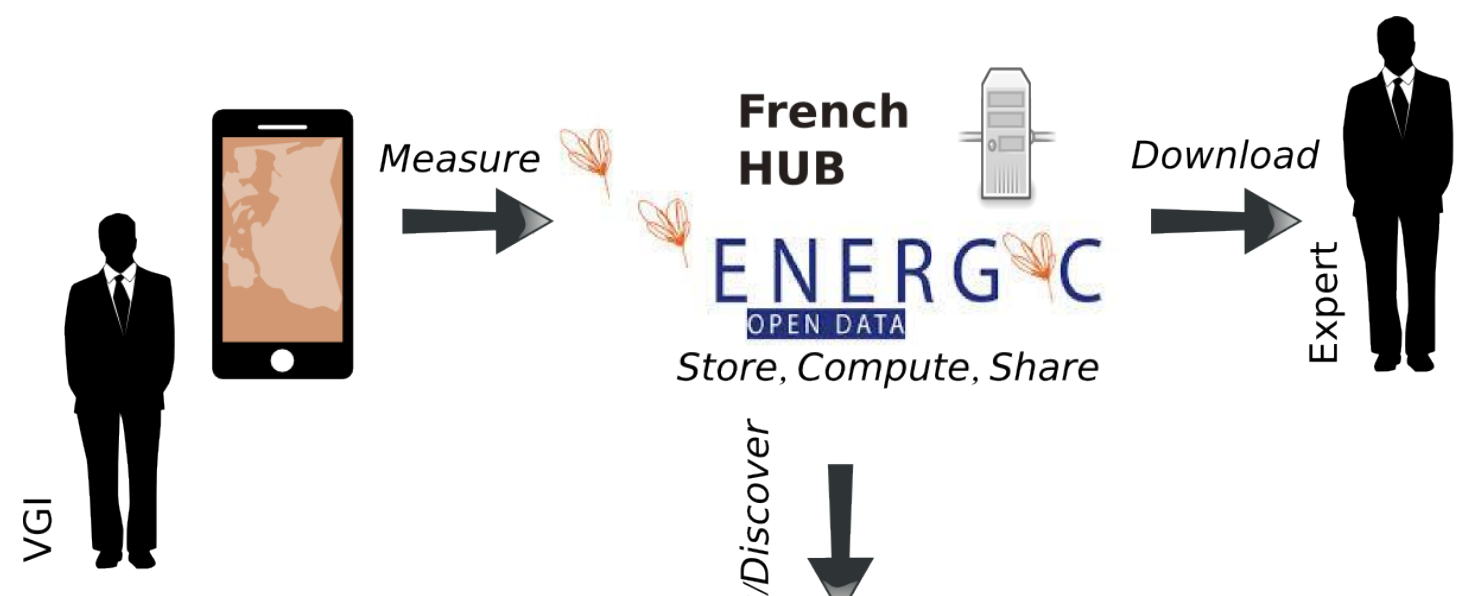

Store, Compute, Share
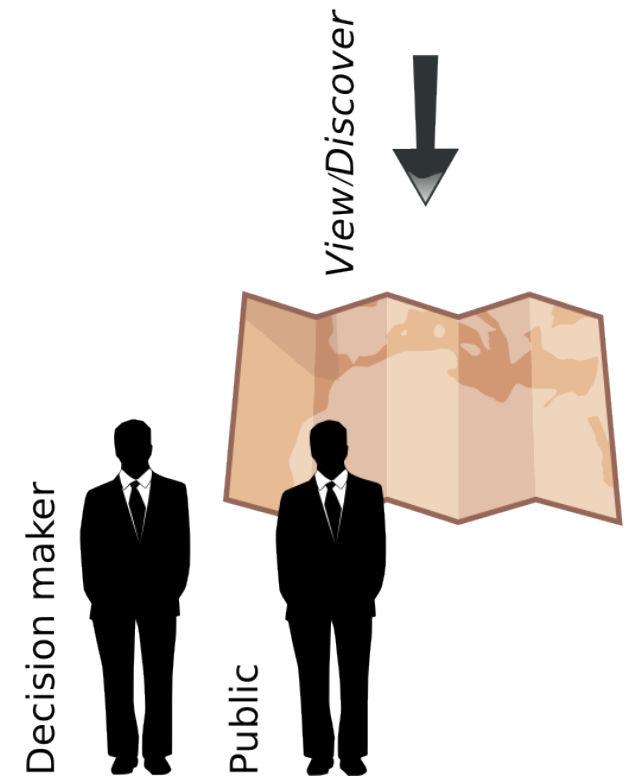

Figure 3. The four levels of stakeholders.

\section{The Decision Maker}

The Decision Maker is a stakeholder who can be in a public authority or in a company. He is using the visualization services (web map viewer) to see and understand the noise map exposure on its territory. He can also use this kind of information to take or support a decision.

\section{The Public}

The Public is made of citizens or of civil society organisations. They mainly use the visualization services to be aware of noise issues.

\section{The Expert}

The expert is someone (geographer, acoustician ...) who is able to understand and manage the raw data, extracted from the database, and to use it in its domain of application to produce added value data (e.g. identify places where the noise exposure is too high, or analyse the evolution of the noise exposure on several years...). 


\section{Mapping sound indicators}

Both acoustical and statistical indicators are computed for the whole duration of the measurement. E.g. $\mathrm{L}_{A 10}$ that represents the peak noise, $\mathrm{L}_{A 50}$ the mean value of the noise levels and $\mathrm{L}_{A 90}$ the mean value of the background noise (Figure 2(b)).

A first native map is rendered to represent a classification of five sound levels as follows (Figure 4):

$$
\text { [<45 } d B(A)],[45-55 d B(A)],[55-65 d B(A)],[65-75 d B(A)],[>75 d B(A)]
$$

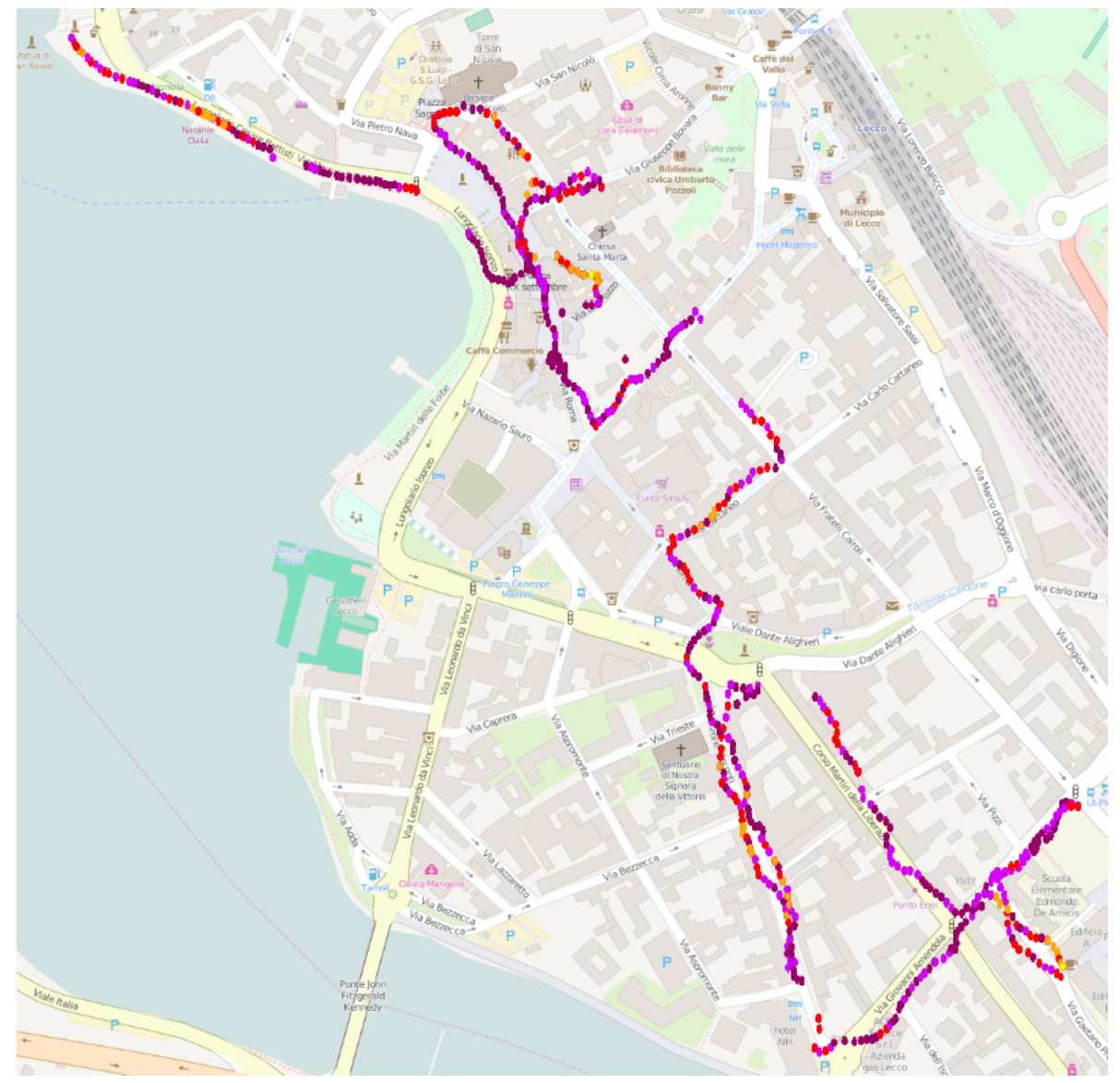

Figure 4. Aggregated WMS layers : OSM and Noise measurements in the italian city of Lecco.

The statistical indicators can also be evaluated by connecting the noise data with geographical and population data. For example, population exposure can be reckoned by confronting noise data with land-use rates data. Thus, an estimation of the inhabitants exposed to ranged noise levels (i.e. the distribution of noise exposure in the population) is allowed by combining the sound levels (e.g. the Lden values) comprised within a range of values over the studied territory and its demographic distribution (Figure 5). 


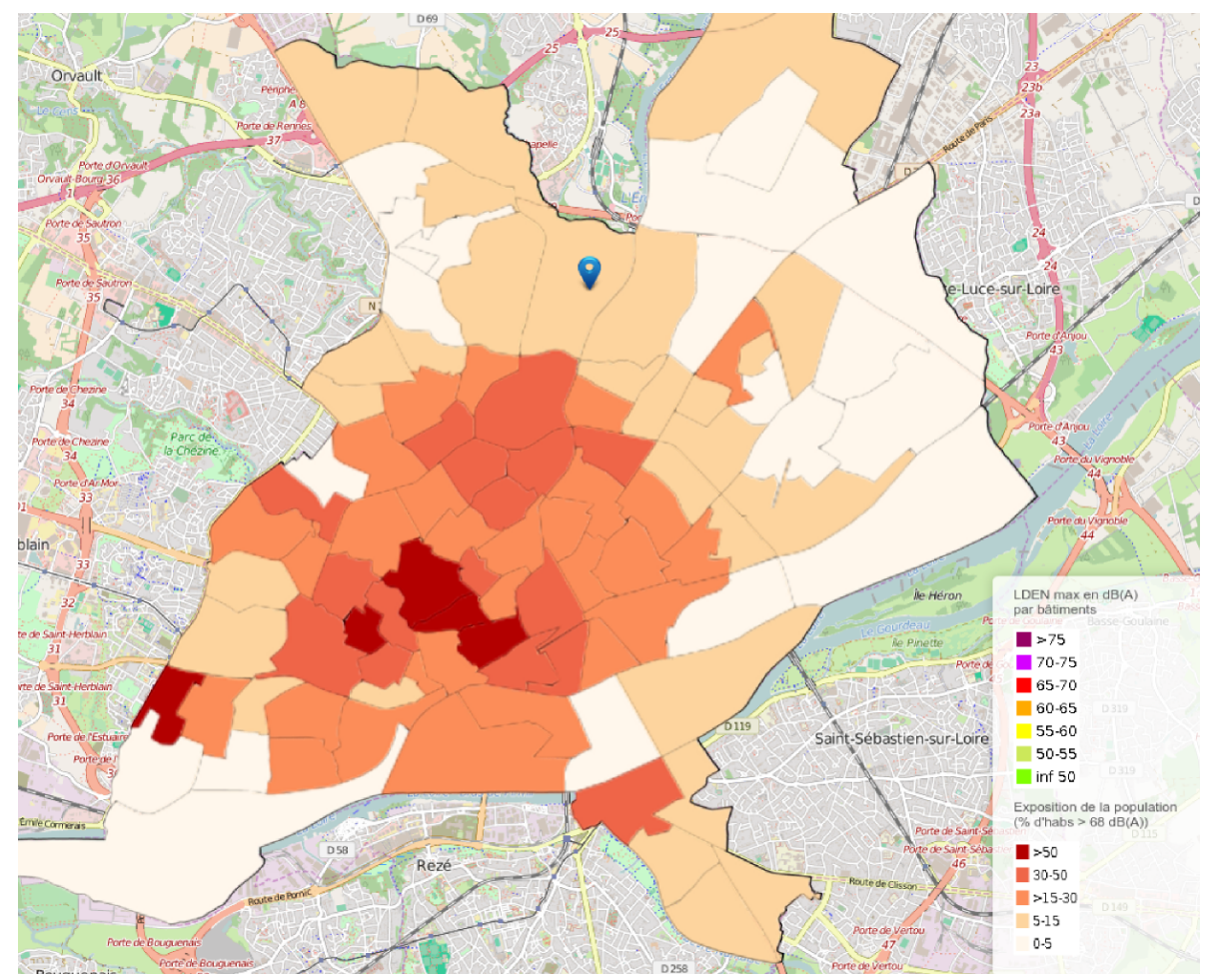

Figure 5. Aggregated WMS layers: OSM and noise population exposure, at IRIS (aggregated units for statistical information) scale in the french city of Nantes.

Compute indicators from collected smartphone data is one of the big challenge of the OnoM@p platform and need new methods and techniques:

- to express evolution and changes,

- to build consistent analysis of spatial and temporal variation,

- to find the best geographic unit to maximize cross-temporal comparability.

\section{CONCLUSION}

The OnoM@p Spatial Data Infrastructure is a very promising tool for the environmental noise monitoring. It offers solutions both for the experts and the community, in order to evaluate the noise annoyance, as well as the noise exposure. Comparing with classical noise evaluation methods, based on numerical simulations (with a limited number of sound sources, in a simplified urban area, with approximated noise propagation models), the proposed methodology enabled to present the 'real' state of the noise exposure, based on real measurements. In addition, since measurements can be carried out everywhere, it allows to produce a noise evaluation that is not restricted to urban areas.

In an acoustics point of view, one challenge (i.e. one criticism too) is still the quality of the noise measurement, since smartphone capabilities can not be compared to professional sonometers. 
Although recent technical developments seems to show that, in a few years, this will no longer be a problem, one can proposed original solutions to post-process measurements, using for example a cross-calibration procedure of all mobile measurements, using an in-situ sensors network (Can et al., 2016). Beyond the acoustic measurement, the last challenge could be to offer to the community and to the experts, simple and relevant representations of sound environment, which are not limited to noise indicators (i.e. physical measurement), but to the perceived environment. The choice of appropriate and simple spatial representations, associated with the ability to cross acoustic indicators with other geo-referenced data, clearly shows that geomatics has become today an essential component in the assessment, thus the reduction, of noise in the environment.

\section{FUNDING STATEMENT}

The ENERGIC-OD Project (European Network for Redistributing Geospatial Information to user Communities - Open Data) is partially funded under the ICT Policy Support Programme (ICT PSP) as part of the Competitiveness and Innovation Framework Programme by the European Community. The present work is also supported by the French geographic portal GÉOPAL of the Pays de la Loire region.

\section{REFERENCES}

Adeel, U., Yang, S., and McCann, J. A. (2014). Self-optimizing citizen-centric mobile urban sensing systems. In 11th International Conference on Autonomic Computing (ICAC 14), pages 161-167, Philadelphia, PA. USENIX Association.

Andrew T. Campbell, Shane B. Eisenman, N. D. L. E. M. and Peterson, R. A. (2006). People-centric urban sensing. In In: Second ACM/IEEE International Conference on Wireless Internet (WiCon 2006), Boston, August 2-5, 2006.

Becker, M., Caminiti, S., Fiorella, D., Francis, L., Gravino, P., Haklay, M. M., Hotho, A., Loreto, V., Mueller, J., Ricchiuti, F., Servedio, V. D. P., Sîrbu, A., and Tria, F. (2013). Awareness and learning in participatory noise sensing. PLOS ONE, 8(12):1-12.

Bocher, E. and Petit, G. (2013). ORBISGIS: Geographical Information System Designed by and for Research. In Innovative Software Development in GIS. Wiley.

Bocher, E., Petit, G., Fortin, N., and Palominos, S. (2015). H2GIS a spatial database to feed urban climate issues. In 9th International Conference on Urban Climate (ICUC9), Toulouse, France. Météo-France.

Burke, J., Estrin, D., Hansen, M., Parker, A., Ramanathan, N., Reddy, S., and Srivastava, M. B. (2006). Participatory sensing. In In: Workshop on World-Sensor-Web (WSW'06): Mobile Device Centric Sensor Networks and Applications, pages 117-134.

Can, A., Guillaume, G., and Picaut, J. (2016). Cross-calibration of participatory sensor networks for environmental noise mapping. Applied Acoustics, 110:99 - 109.

Conrad, C. C. and Hilchey, K. G. (2011). A review of citizen science and community-based environmental monitoring: issues and opportunities. Environmental Monitoring and Assessment, 176(1):273-291.

Cuff, D., Hansen, M., and Kang, J. (2008). Urban sensing: Out of the woods. Commun. ACM, 51(3):24-33. 
D’Hondt, E., Stevens, M., Jacobs, A., Calabrese, F., Conti, M., Dahlem, D., Lorenzo, G., and Phithakkitnukoon, S. (2013). Participatory noise mapping works! an evaluation of participatory sensing as an alternative to standard techniques for environmental monitoring. Pervasive and Mobile Computing, 9(5):681-694. Francesco Calabrese, Marco Conti, Dominik Dahlem, Giusy Di Lorenzo, Santi Phithakkitnukoon.

Drosatos, G., Efraimidis, P. S., Athanasiadis, I. N., Stevens, M., and D'Hondt, E. (2014). Privacypreserving computation of participatory noise maps in the cloud. Journal of Systems and Software, 92:170 - 183 .

Guillaume, G., Can, A., Petit, G., Fortin, N., Palominos, S., Gauvreau, B., Bocher, E., and Picaut, J. (2016). Noise mapping based on participative measurements. Noise Mapping, 3:140-156.

Kanjo, E. (2010). Noisespy: A real-time mobile phone platform for urban noise monitoring and mapping. Mobile Networks and Applications, 15(4):562-574.

Kanjo, E., Bacon, J., Roberts, D., and Landshoff, P. (2009). Mobsens: Making smart phones smarter. IEEE Pervasive Computing, 8(4):50-57.

Leao, S. and Zhou., W. (2014). Monitoring exposure to traffic noise with mobile phones in china: A review of context. International Journal of Information and Computer Science, pages 52-63.

Maisonneuve, N., Stevens, M., and Ochab, B. (2010). Participatory noise pollution monitoring using mobile phones. Info. Pol., 15(1,2):51-71.

Mohammadi, H., Rajabifard, A., and Williamson, I. (2008). Spatial Data Integrability and Interoperability in the Context of SDI, pages 401-413. Springer Berlin Heidelberg, Berlin, Heidelberg.

Neis, P. and Zipf, A. (2012). Analyzing the contributor activity of a volunteered geographic information project - the case of openstreetmap. ISPRS International Journal of Geo-Information, $1(2): 146$.

Nugent, C. and Stanners, D. (2014). Noisewatch. In Citizen Observatories: Empowering European Society, Brussels, Belgium.

Ruge, L., Altakrouri, B., and Schrader, A. (2013). Soundofthecity - continuous noise monitoring for a healthy city. In Pervasive Computing and Communications Workshops (PERCOM Workshops), 2013 IEEE International Conference on, pages 670-675.

Steiniger, S. and Hunter, A. J. S. (2012). Free and Open Source GIS Software for Building a Spatial Data Infrastructure, pages 247-261. Springer Berlin Heidelberg, Berlin, Heidelberg.

Wisniewski, M., Demartini, G., Malatras, A., and Cudré-Mauroux, P. (2013). NoizCrowd: A Crowd-Based Data Gathering and Management System for Noise Level Data, pages 172-186. Springer Berlin Heidelberg, Berlin, Heidelberg. 